\title{
ABSORÇÃO DE N, P E K POR ESPÉCIES DE ADUBOS VERDES CULTIVADAS EM DIFERENTES É POCAS E DENSIDADES NUM LATOSSOLO VERMELHO-ESCURO ARGILOSO SOB CERRADOS ${ }^{(1)}$
}

\author{
R. F. AMABILE (2), A. L. FANCELLI (3) \& A. M. CARVALHO(2)
}

\begin{abstract}
RESUMO
Populações específicas de plantas e a época de semeadura podem promover interferências na absorção dos nutrientes. Assi m, um experimento foi realizado, no ano agrícola de 1991/92, num Latossolo Vermelho-E scuro argi loso no Centro Nacional de Pesquisa de Solos/E mbrapa, em Senador Canedo (GO), com o objetivo de determinar os teores e as quantidades absorvidas de nitrogênio, fósforo e potássio na parte aérea da Crotalaria juncea L., Crotalaria ochroleuca G. Don, mucuna preta (Mucuna aterrima (Piper \& Tracy) Merr.) e guandu cv. Kaki (Cajanus cajan (L.) Millsp.), em três épocas de semeadura (início, meados e final da estação chuvosa) e em dois espaçamentos entrelinhas (0,5 e 0,4 m). 0 delineamento experimental, dentro de cada época, foi o de blocos ao acaso em parcelas subdi vididas, com três repetições. As espécies diferiram entre si quanto aos teores e quantidades absorvidas de N, P e K. Ao contrário das épocas de semeadura, não houve efeito significativo dos espaçamentos nos teores e quantidades absorvidas de N, P e K. A interação de espécies e épocas de semeadura foi significativa apenas para o nitrogênio e fósforo.
\end{abstract}

Termos de indexação: adubação verde, população, nitrogênio, fósforo, potássio, Crotalaria juncea, Crotalaria ochroleuca, Mucuna aterrima, Cajanus cajan.

(1) Parte da Tese de Mestrado do primeiro autor apresentada à Escola Superior de Agricultura "Luiz de Queiroz" da Universidade de São Paulo. Recebido para publicação em novembro de 1998 e aprovado em maio de 1999.

(2) Pesquisador da Embrapa Cerrados. Caixa Postal 70.023, CEP 73301-970 Planaltina (DF). E-mail: amabile@cpac.embrapa.br.

(3) Professor Doutor do Departamento deAgricultura, Escola Superior deAgricultura "Luiz deQueiroz"/USP. Caixa Postal 9, CEP 13418900 Piracicaba (SP). 


\title{
SUMMARY: UPTAKE OF N, P AND K BY GREEN MANURE SPECIES UNDER DIFFERENT SOWING TIMES AND PLANTING SPACINGS IN CERRADO SOIL
}

\begin{abstract}
Planting spacings and sowing dates may influence nutrient absorption. Ther efore, a field experiment was carried out from 1991 to 1992, at theexperimental station of Embrapa/ Soil Research National Center, located in Senador Canedo, Goiás, Brazil, to determi nethe $\mathrm{N}, \mathrm{P}$ and $\mathrm{K}$ uptake levels in the aerial part of sunhemp (Crotalaria juncea), Crotalaria ochrol euca, black vel vet bean (Mucuna aterrima) and pigeonpea cv. Kaki (Cajanus cajan), under threesowing times (beginning, middleand end of thegrowing season) and two spacings between the planting rows. The experiment was arranged in a randomized split pl ot design, with threreplications, with thesowing dates in themain plots and theplanting spacings in thesplit plots. Theresul ts indicated that therethelevel s of N, P and K uptakevaried among the species. N, P and K uptakelevels in thelegume shoot dry matter wereinfluenced by the sowing times, and the species $\mathrm{x}$ sowing time interaction was significant for $\mathrm{N}$ and $\mathrm{P}$. Nevertheless, N, P and K uptake levels were not influenced by the spacings betwen the planting rows.
\end{abstract}

Index terms: population, nitrogen, phosphorus, potassium, Crotalaria juncea, Crotalaria ochroleuca, Mucuna aterrima, Cajanus cajan.

\section{NTRODUÇÃO}

A falta de otimização da interação genótipo $x$ latitudeou época de plantiox densidade populacional (Lawn \& Williams, 1987) influi na absorção de nutrientes e, conseqüentemente, no desenvol vimento e, ou, crescimento das plantas. Bates (1971) destacou que a interação de nutrientes, umidade do ar e do solo, espécie, luz etemperatura influenciam os teores dos el ementos nos tecidos vegetais, apesar de ser a absorção dos nutrientes uma característica intrínseca da espécie. Reddy et al. (1986) avaliaram o efeito de épocas de semeadura sobre os teores de nutrientes de diversas leguminosas e constataram comportamentos distintos entre elas em relação ao teor denitrogênio, no florescimento. Houve, também, diferenças na composição química entre os materiais avaliados, numa mesma época ou entre épocas de semeadura.

O teor de nutrientes nos tecidos das plantas pode ser afetado pelo estresse hídrico a que está submetido (Wilson, 1983; Wilson \& Muchow, 1983; Chapman \& Muchow, 1985; Nandwal et al., 1992), o que, por sua vez, está relacionado com as épocas de semeadura. Sharma et al. (1990), ao estudarem o guandu semeado em datas marginais, constataram interferência de fatores climáticos na absorção de nitrogênio, fósforo e potássio.

Existem, contudo, poucas informações sobre os teores e absorção de nutrientes por espécies de adubos verdes. Magal hães et al. (1991) encontraram teores mais el evados de nitrogênio na parte aérea da crotalária juncea do que da mucuna preta cultivada em um Latossolo Vermel ho-E scuro. Burle et al. (1994a) observaram, na mesma unidade de solo, que a mucuna preta e o guandu acumularam quantidades semel hantes de nitrogênio, quando cultivados no final do período chuvoso. Para a C. juncea semeada no mesmo período, porém em anos diferentes, Patil \& Pal (1985) observaram variações nos teores de nitrogênio, fósforo e potássio. Caceres \& Alcarde (1995) analisaram amostras foliares de mucuna preta, C. juncea e guandu. O teor de fósforo na mucuna preta foi de $2,1 \mathrm{~g} \mathrm{~kg}^{-1}$ e o de potássio de $14,3 \mathrm{~g} \mathrm{~kg}^{-1}$. A C. juncea apresentou $2,6 \mathrm{~g} \mathrm{~kg}^{-1}$ de fósforo e $14,3 \mathrm{~g} \mathrm{~kg}^{-1}$ de potássio, enquanto o guandu, $1,9 \mathrm{~g} \mathrm{~kg}^{-1}$ e de 11,3 $\mathrm{g} \mathrm{kg}^{-1}$, para o fósforo e potássio, respectivamente. Os trabalhos de Hundal \& Dhillon (1993) e Kolar et al. (1993) mostraram, respectivamente, que o teor de nitrogênio na $C$. juncea variou de 23,0 a 27,0 g kg-1 e de 24,0 a 25,0 g kg-1 em função do ambiente e da época de avaliação.

O objetivo do presentetrabal ho foi avaliar o efeito de épocas de semeadura e espaçamentos sobre os teores e quantidades absorvidas de nitrogênio, fósforo e potássio pela Crotalaria juncea, Crotalaria ochroleuca, Mucuna aterrima (mucuna preta) e Cajanus cajan (guandu cv. Kaki), cultivados num Latossolo Vermelho-E scuro argil oso sob cerrados.

\section{MATERIAL E MÉTODOS}

O experimento foi real izado na área da E mbrapa Solos/Coordenadoria Regional Centro-Oeste, localizada na Estação Experimental da EMATERGO, em Senador Canedo (GO), no ano agrícola de 1991/92, num Latossolo Vermel ho-E scuro distrófico A moderado textura argilosa fase cerrado tropical subcaducifólio e rel evo suave ondulado. As análises 
do solo $(0-20 \mathrm{~cm})$, realizadas conforme EMBRAPA (1979), indicaram: $\mathrm{pH}$ em $\mathrm{H}_{2} \mathrm{O}=5,3$; M.O.= $27,2 \mathrm{~g} \mathrm{~kg}^{-1} ; \mathrm{Al}^{+3}=0,05 \mathrm{cmol}_{\mathrm{C}} \mathrm{dm}^{-3} ; \mathrm{H}^{+}=5,5 \mathrm{amol}_{\mathrm{C}} \mathrm{dm}^{-3}$; $\mathrm{Ca}+2=2,2 \mathrm{cmol}_{\mathrm{c}} \mathrm{dm}^{-3} ; \mathrm{Mg}^{+2}=0,5 \mathrm{cmol}_{\mathrm{C}} \mathrm{dm}^{-3} ; \mathrm{P}=$ $8 \mathrm{mg} \mathrm{dm}^{-3} ; \mathrm{K}=0,27 \mathrm{cmol}_{\mathrm{c}} \mathrm{dm}^{-3}$; areia grossa $=$ $90 \mathrm{~g} \mathrm{~kg}^{-1}$; areia fina $=240 \mathrm{~g} \mathrm{~kg}^{-1}$; silte $=160 \mathrm{~g} \mathrm{~kg}^{-1}$; argila $=510 \mathrm{~g} \mathrm{~kg}^{-1}$. O clima, conforme a classificação de Köppen, é do tipo Aw. Os dados meteorológicos foram coletados no decorrer dos experimentos (Figuras 1, 2 e 3).

O delineamento experimental utilizado, dentro de cada época, foi o de blocos ao acaso com parcelas subdivididas, aplicando as espécies nas parcelas e os espaçamentos nas subparcelas, perfazendo um grupo de três experimentos. A área total da parcela foi de $32 \mathrm{~m}^{2}$, enquanto a da subparcela foi de $16 \mathrm{~m}^{2}$, com uma área útil de $9 \mathrm{~m}^{2}$.
O preparo do sol ofoi feito por meio de uma aração, com arado de discos de 32" e de uma gradagem com grade de discos de 20", seguido da abertura de sulcos nos espaçamentos de 0,40 e 0,50 m. As quantidades aplicadas de fósforo e potássio foram determinadas com base nos resultados das análises do solo e constaram de $50 \mathrm{~kg} \mathrm{ha}-1$ de $\mathrm{P}_{2} \mathrm{O}_{5}$ (superfosfato simples) e de $30 \mathrm{~kg} \mathrm{ha}-1$ de $_{2} \mathrm{O}$ (cloreto de potássio) aplicados no sulco de semeadura.

As espécies estudadas foram a Crotalaria juncea, Crotalaria ochroleuca, Mucuna aterrima (mucuna preta), Cajanus cajan (guandu cv. Kaki), semeadas em três épocas da estação chuvosa: início (12/11/ 1991); meados (7/1/1992) efinal (4/3/1992). A mucuna preta, por apresentar dormência, recebeu tratamento específico, conforme Maeda \& Lago (1986).

(a)

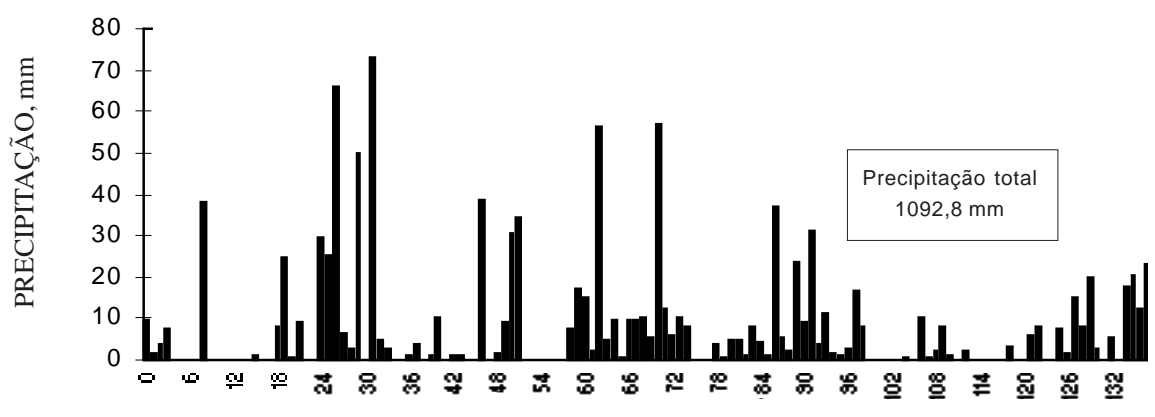

(b)
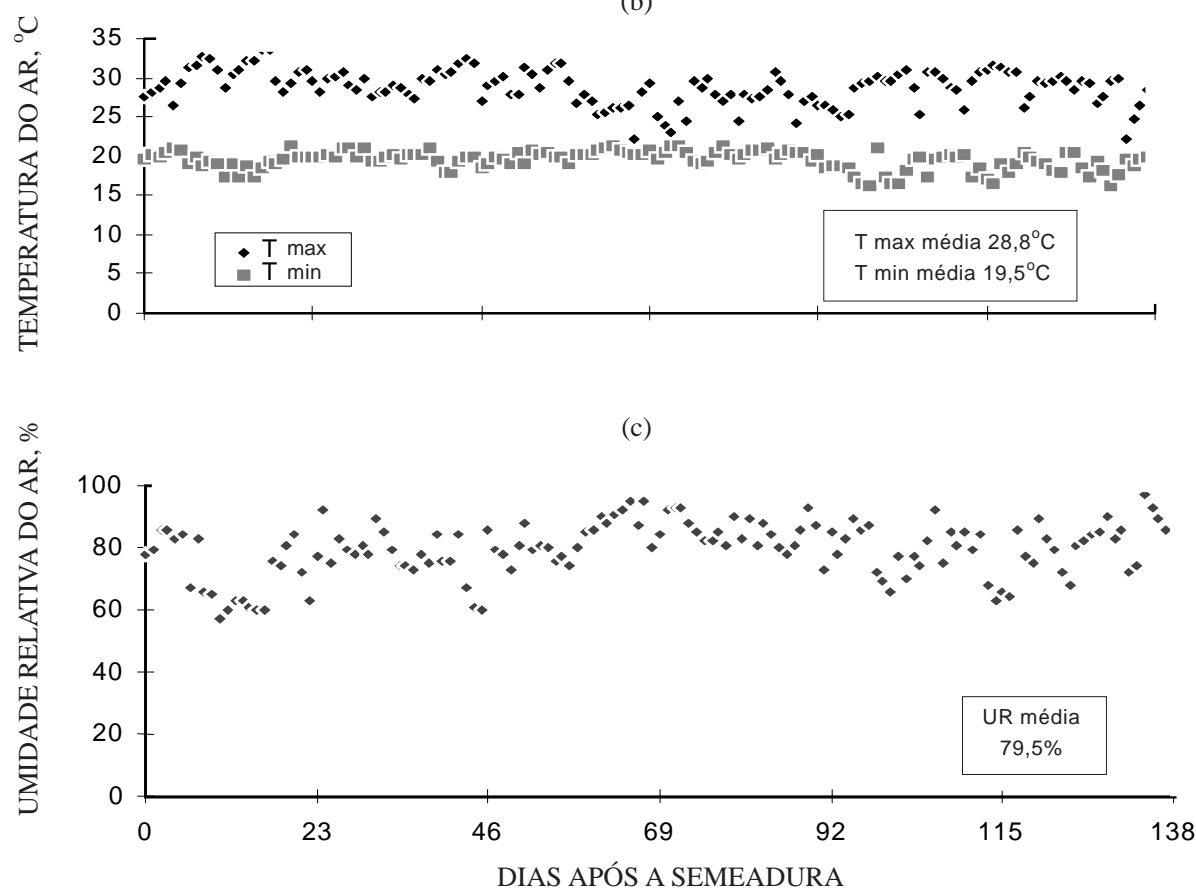

Figura 1. Elementos do clima durante a primeira época de semeadura (12 de novembro de 1991): (a) precipitação ( $\mathrm{mm} \mathrm{dia}^{-1}$ ); (b) temperaturas máximas e mínimas do ar (으); (c) umidade relativa média do ar (\%). 

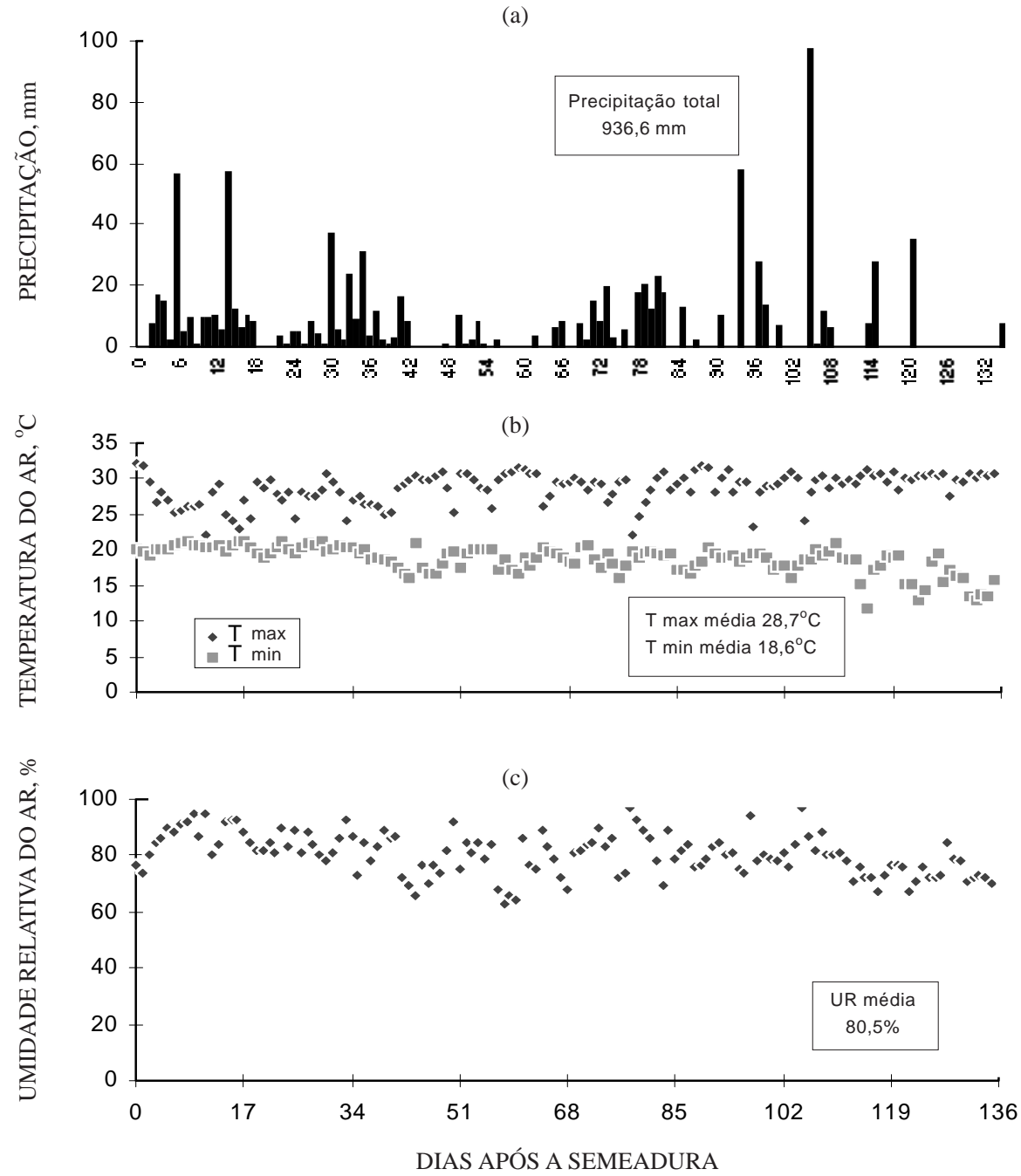

Figura 2. Elementos do clima durante a segunda época de semeadura (7 de janeiro de 1992): (a) precipitação $\left(\mathrm{mm} \mathrm{dia}^{-1}\right)$; (b) temperaturas máximas e mínimas do ar (ㅇ); (c) umidade relativa média do ar (\%).

A semeadura foi realizada com uma semeadora experimental de uma linha, com uma densidade de sementes $20 \%$ superior à densidade de plantas planejada. Após dez dias da emergência, executouse o desbaste, estabelecendo um estande de 25 plantas/metro, para a C. juncea e C. ochrol euca; 10 plantas/metro, para a M. aterrima, e 30 plantas/ metro, para o C. cajan. As populações de plantas obtidas, por hectare, no espaçamento de $0,40 \mathrm{~m}$ foram de 625.000, para a C. juncea e para a C. ochrol euca; 250.000, para a mucuna preta, e 750.000, para o guandu. Para o espaçamento de $0,50 \mathrm{~m}$, as populações de plantas por hectare foram de 500.000 , para a C. juncea e para a C. ochroleuca; de 200.000, para a mucuna preta, e de 600.000, para o guandu.

No florescimento, as plantas da área útil decada subparcela foram cortadas rente ao sol o e levadas à estufa de ventilação a $65^{\circ} \mathrm{C}$, para secagem até peso constante. As determinações dos teores denitrogênio, fósforo e potássio nos teci dos vegetais da parteaérea foram realizadas conforme a técnica descrita por Sarruge \& Haag (1974), eas quantidades absorvidas foram calculadas em função da matéria seca produzida por cada material.

Os dados foram submetidos às análises de variância individuais e conjunta. As médias foram comparadas entre si pelo teste de Tukey a 5\%.

\section{RESULTADOS E DISCUSSÃO}

Efeitos significativos das espécies e das épocas de semeadura foram observados para todos os nutrientes, tendo sido a interação entre eles significativa somente para o nitrogênio e fósforo 
(a)
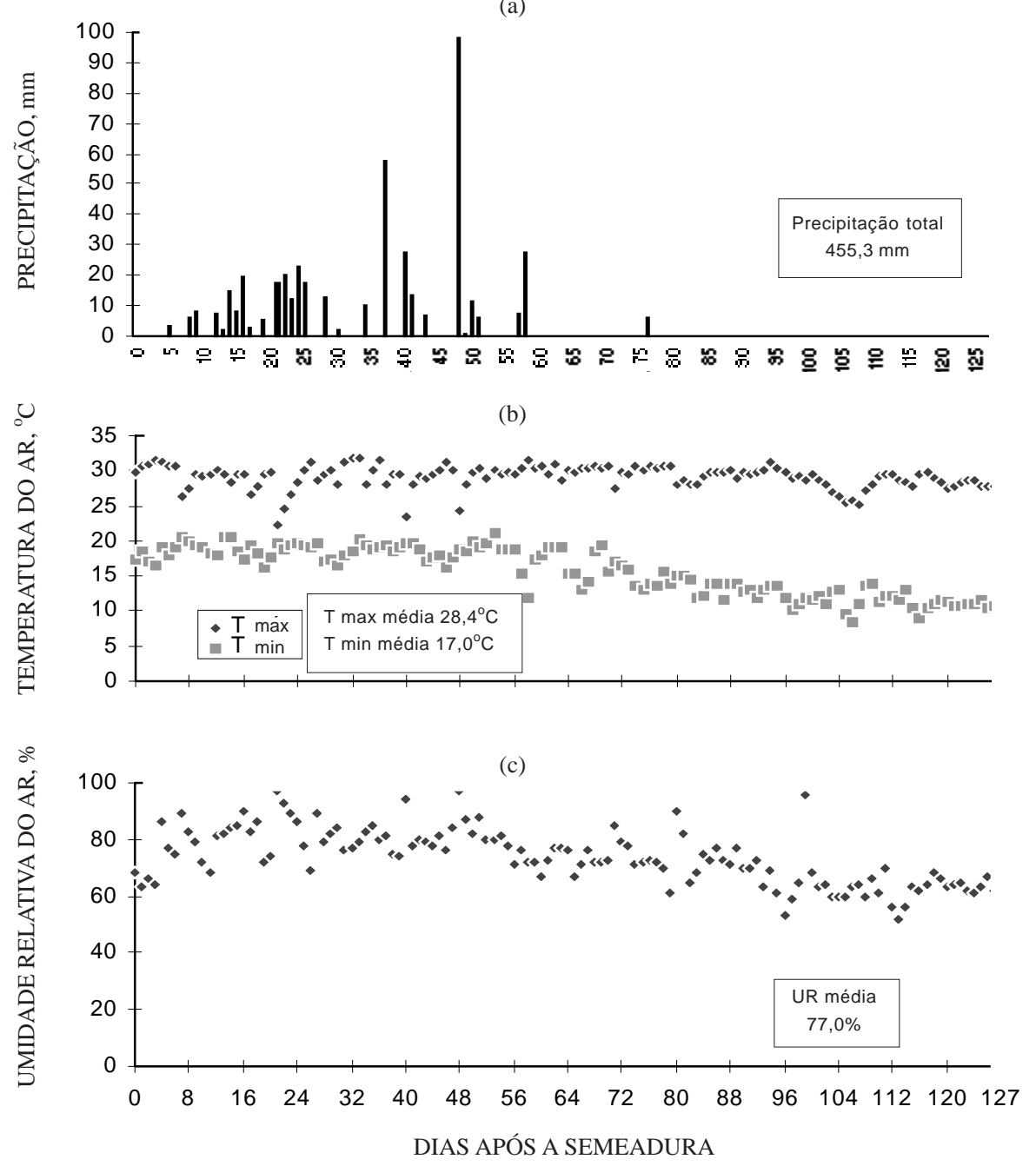

Figura 3. E lementos do clima durante a terceira época de semeadura (4 de março de 1992): (a) preci pitação ( $\left.\mathrm{mm} \mathrm{dia}^{-1}\right)$; (b) temperaturas máximas e mínimas do ar (oC); (c) umidade relativa média do ar (\%).

(Quadro 1). Houve diferença no teor e absorção de nitrogênio, fósforo e potássio entre as espécies, uma vez que el as apresentam comportamento diferenciado na fixação de nitrogênio e na absorção, transportee redistribuição desses el ementos (Malavolta, 1980; Reddy et al.,1986; Sousa \& Lobato, 1988; Raij, 1991).

Ao mesmo tempo, a variação climática ocorrida entre as épocas de semeadura, como a ação fotoperiódica ea preci pitação, também interferiu nos teores e na absorção dos nutrientes pelos adubos verdes, concordando com as afirmações de Bates (1971) e Malavolta et al. (1989).

Os teores e as quantidades absorvidas de nitrogênio e fósforo não foram os mesmos nas diferentes espécies eépocas testadas. Essa interação foi influenciada igualmente pelas diferentes condições climáticas ocorridas na condução dos ensaios e pela grande variabilidade genética das leguminosas. Raij (1991) atribuiu à interação planta $x$ ambiente a variação dos teores de nitrogênio nas plantas. Baligar et al. (1990) citaram que espécies, cultivares e genótipos interagem com o ambiente, resul tando em diferenças na absorção e, ou, utilização de nutrientes como o fósforo.

Não houve significância para a interação de espécie e época em relação ao teor e à absorção de potássio, sugerindo a estabilidade dos adubos verdes, para esse el emento, nas condições estudadas.

Os teores e as quantidades absorvidas de nitrogênio, fósforo e potássio não foram afetados pelos espaçamentos e, conseqüentemente, pelas populações empregadas (Quadro 1). As interações de épocas e espaçamentos, espécies e espaçamentos, além da interação tripla entre esses parâmetros, não 
Quadro 1. Análise de variância conjunta dos valores de absorção e de teor de nitrogênio, fósforo e potássio na parte aérea das espécies de adubos verdes Crotalaria juncea, Crotalaria ochroleuca, Mucuna aterrima e Cajanus cajan

\begin{tabular}{|c|c|c|c|c|c|c|}
\hline \multirow[b]{2}{*}{ F.v. } & \multicolumn{2}{|c|}{ Nitrogênio } & \multicolumn{2}{|c|}{ Fósforo } & \multicolumn{2}{|c|}{ Potássio } \\
\hline & $\begin{array}{c}\text { Teor } \\
\text { F }\end{array}$ & $\begin{array}{c}\text { Absor ção } \\
\text { F }\end{array}$ & $\begin{array}{c}\text { Teor } \\
\text { F }\end{array}$ & $\begin{array}{c}\text { Absorção } \\
\text { F }\end{array}$ & $\begin{array}{c}\text { Teor } \\
\text { F }\end{array}$ & $\begin{array}{c}\text { Absor ção } \\
\text { F }\end{array}$ \\
\hline $\begin{array}{l}\text { É poca (E p) } \\
\text { Bloco/época } \\
\text { E spécie (E s) } \\
\text { Es* E p }\end{array}$ & $\begin{array}{c}* * \\
\text { ns } \\
* * \\
*\end{array}$ & $\begin{array}{c}* * \\
\text { ns } \\
* * \\
*\end{array}$ & $\begin{array}{c}* * \\
\mathrm{~ns} \\
* \\
* *\end{array}$ & $\begin{array}{c}* * \\
\mathrm{~ns} \\
* \\
* *\end{array}$ & $\begin{array}{c}* * \\
\text { ns } \\
* \\
\text { ns }\end{array}$ & $\begin{array}{c}* * \\
\text { ns } \\
* \\
\text { ns }\end{array}$ \\
\hline \multicolumn{7}{|l|}{ Resíduo a } \\
\hline $\begin{array}{l}\text { Espaçamento (D) } \\
\text { Ep* D }\end{array}$ & $\begin{array}{l}\text { ns } \\
\text { ns }\end{array}$ & $\begin{array}{l}\text { ns } \\
\text { ns }\end{array}$ & $\begin{array}{l}\text { ns } \\
\text { ns }\end{array}$ & $\begin{array}{l}\text { ns } \\
\text { ns }\end{array}$ & $\begin{array}{l}\text { ns } \\
\text { ns }\end{array}$ & $\begin{array}{l}\text { ns } \\
\text { ns }\end{array}$ \\
\hline \multicolumn{7}{|l|}{ Resíduo b } \\
\hline $\begin{array}{l}E s * D \\
E s * D * E p\end{array}$ & $\begin{array}{l}\text { ns } \\
\text { ns }\end{array}$ & $\begin{array}{l}\text { ns } \\
\text { ns }\end{array}$ & $\begin{array}{l}\text { ns } \\
\text { ns }\end{array}$ & $\begin{array}{l}\text { ns } \\
\text { ns }\end{array}$ & $\begin{array}{l}\text { ns } \\
\text { ns }\end{array}$ & $\begin{array}{l}\text { ns } \\
\text { ns }\end{array}$ \\
\hline \multicolumn{7}{|l|}{ Resíduo c } \\
\hline C.V. Total \% & 13,7 & 9,9 & 7,2 & 10,8 & 22,2 & 17,5 \\
\hline
\end{tabular}

foram significativas, indicando a ausência de uma associação entre a população empregada e o ambiente, com os teores eabsorção desses el ementos.

A mucuna preta e o guandu, ao contrário das observações de Reddy et al. (1986) edeBalakrishnan \& Natarajaratnam (1989), não apresentaram relação de dependência entre o teor de $\mathrm{N}$ e as épocas de semeadura. Ao mesmo tempo, a ampla variabilidade existente dentro dos genótipos da mucuna preta e do guandu faz com que haja materiais mais adaptados à variação temporal do que outros, promovendo, por vezes, uma uniformi dadenos teores de nitrogênio total dessas espécies. A C. juncea e a C. ochroleuca aumentaram significativamente a concentração de nitrogênio com o atraso das semeaduras, demonstrando a influência das condições climáticas sobre o teor de $\mathrm{N}$ total dessas leguminosas (Quadro 2).

Dentro de cada época (Quadro 2), a mucuna preta obteve teores maiores de $\mathrm{N}$ que a $\mathrm{C}$. juncea, à semel hança dos obtidos por Quintana (1987), exceto na semeadura da terceira época, quando as quatro leguminosas comportaram-se de modo semel hante. Resultados similares foram obtidos por Pereira (1991) e Burle et al. (1994a). Burle et al. (1994b) obtiveram para o guandu e a mucuna preta, semeados no final da estação chuvosa dos Cerrados, valores de $\mathrm{N}$ semel hantes. Os teores médios encontrados para o guandu estão dentro do intervalo obtido por Bahar (1981), porém inferiores ao nível crítico, de37,3 $\mathrm{g} \mathrm{kg}^{-1}$, indicado por Ogata et al. (1988). Para a C. juncea, os teores foram inferiores aos apresentados por Patil \& Pal (1985), mas semel hantes aos deHundal \& Dhillon (1993) e Kolar et al. (1993).

No que se refere à absorção de nitrogênio, dentro de cada época de semeadura, constatou-se um efeito das espécies, tendo as maiores quantidades de nitrogênio sido al cançadas na primeira época, pelo guandu e C. juncea, em função do maior índice de precipitação ocorrido nesse período na região, que contribuiu para mai or produção de matéria seca. $\mathrm{Na}$ terceira época de semeadura, não houve diferenças significativas entre as espécies avaliadas (Quadro 2).

A absorção de fósforo pel o guandu decresceu com - avançar das épocas de semeadura, indicando a existência de uma relação entre as épocas de semeadura e a absorção de fósforo, a exemplo da relação encontrada em Wilson, (1983); Bhowmik et al. (1983) e Sharma et al. (1990). A mesma resposta ocorreu para a C. juncea.

Quanto à avaliação do teor de fósforo das leguminosas, dentro de cada época de semeadura, foram constatadas diferenças significativas apenas na primeira época, quando o guandu apresentou teores mais el evados desse nutrientena parteaérea (Quadro 3). A pequena heterogeneidade do teor de fósforo verificada entre as espécies, para todas as épocas de semeadura, com exceção do guandu para a primeira época, não indica uma espécie como sendo a mais eficaz em acumular fósforo na parte aérea.

Os teores de fósforo da mucuna preta, nas diversas épocas, estão abaixo do encontrado por Caceres \& Alcarde (1995), que foi de $2,1 \mathrm{~g} \mathrm{~kg}^{-1}$. J á, 
Quadro 2. Valores de absorção e de teor de nitrogênio na parte aérea das espécies de adubos verdes Crotalaria juncea, Crotalaria ochroleuca, Mucuna aterrima e Cajanus cajan

\begin{tabular}{|c|c|c|c|c|c|c|}
\hline \multirow{3}{*}{ Espécie } & \multicolumn{6}{|c|}{ É poca de semeadura(1) } \\
\hline & \multicolumn{2}{|c|}{$12 /$ novembro } & \multicolumn{2}{|c|}{ 07/janeiro } & \multicolumn{2}{|c|}{ 04/março } \\
\hline & Teor & Absorção & Teor & Absorção & Teor & Absor ção \\
\hline & $\mathrm{g} \mathrm{kg}^{-1}$ & $\mathrm{~kg} \mathrm{ha}^{-1}$ & $\mathrm{~g} \mathrm{~kg}^{-1}$ & $\mathrm{~kg} \mathrm{ha}^{-1}$ & $\mathrm{~g} \mathrm{~kg}^{-1}$ & $\mathrm{~kg} \mathrm{ha}^{-1}$ \\
\hline C. juncea & $14,7 \mathrm{~b}$ & $248,95 \mathrm{Aa}$ & $15,4 \mathrm{~b}$ & $258,92 \mathrm{Aa}$ & $22,0 \mathrm{a}$ & $113,11 \mathrm{Ba}$ \\
\hline C. ochroleuca & $15,6 \mathrm{~b}$ & $135,01 \mathrm{Ab}$ & $20,2 a b$ & $113,21 \mathrm{Bb}$ & $23,2 \mathrm{a}$ & $101,02 \mathrm{Ba}$ \\
\hline Mucuna preta & 21,6 a & $76,79 \mathrm{Ab}$ & 23,1 a & $93,44 \mathrm{Ab}$ & 24,5 a & $98,37 \mathrm{Aa}$ \\
\hline Guandu & $19,7 \mathrm{ab}$ & $253,66 \mathrm{Aa}$ & $23,2 a$ & $123,68 \mathrm{Bb}$ & 19,6 a & $131,81 \mathrm{Ba}$ \\
\hline C.V. \% & 7,5 & 10,2 & 9,4 & 10,7 & 14,9 & 17,8 \\
\hline
\end{tabular}

(1) Val ores seguidos das mesmas letras maiúsculas, nas linhas, e das letras minúsculas, nas colunas, não diferem entre si pelo teste de Tukey a $5 \%$.

Quadro 3. Valores de absorção e de teor de fósforo na parte aérea das espécies de adubos verdes Crotalaria juncea, Crotalaria ochroleuca, Mucuna aterrima e Cajanus cajan

\begin{tabular}{|c|c|c|c|c|c|c|}
\hline \multirow{3}{*}{ Espécie } & \multicolumn{6}{|c|}{ É poca de semeadura ${ }^{(1)}$} \\
\hline & \multicolumn{2}{|c|}{$12 /$ novembro } & \multicolumn{2}{|c|}{ 07/janeiro } & \multicolumn{2}{|c|}{ 04/março } \\
\hline & Teor & Absor ção & Teor & Absor ção & Teor & Absorção \\
\hline & $\mathrm{g} \mathrm{kg}^{-1}$ & $\mathrm{~kg} \mathrm{ha}^{-1}$ & $\mathrm{~g} \mathrm{~kg}^{-1}$ & $\mathrm{~kg} \mathrm{ha}^{-1}$ & $\mathrm{~g} \mathrm{~kg}^{-1}$ & $\mathrm{~kg} \mathrm{ha}^{-1}$ \\
\hline $\begin{array}{l}\text { C. juncea } \\
\text { C. ochroleuca } \\
\text { Mucuna preta } \\
\text { Guandu } \\
\text { C.V. \% }\end{array}$ & $\begin{array}{l}1,5 \mathrm{~b} \\
1,3 \mathrm{~b} \\
1,4 \mathrm{~b} \\
2,4 \mathrm{a} \\
7,1\end{array}$ & $\begin{array}{r}25,09 \mathrm{Aa} \\
11,52 \mathrm{Ab} \\
4,95 \mathrm{Ab} \\
30,24 \mathrm{Aa} \\
12,8\end{array}$ & $\begin{array}{l}1,7 \mathrm{a} \\
2,1 \mathrm{a} \\
1,8 \mathrm{a} \\
2,1 \mathrm{a} \\
7,2\end{array}$ & $\begin{array}{l}13,39 \mathrm{Bb} \\
11,65 \mathrm{Ab} \\
7,45 \mathrm{Ab} \\
23,06 \mathrm{Aa} \\
14,1\end{array}$ & $\begin{array}{l}1,2 \mathrm{a} \\
1,2 \mathrm{a} \\
1,4 \mathrm{a} \\
1,0 \mathrm{a} \\
7,1\end{array}$ & $\begin{array}{r}7,50 \mathrm{Ca} \\
5,04 \mathrm{Ba} \\
5,76 \mathrm{Aa} \\
6,03 \mathrm{Ba} \\
12,4\end{array}$ \\
\hline
\end{tabular}

(1) Valores seguidos das mesmas letras maiúsculas, nas linhas, e das letras minúsculas, nas colunas, não diferem entre si pelo teste de Tukey a $5 \%$.

para o guandu, os teores das duas primeiras épocas situam-se acima do valor considerado como adequado (1,2 $\left.\mathrm{g} \mathrm{kg}^{-1}\right)$ por Reuter (1986). Para a terceira época de semeadura, o teor de fósforo do guandu foi considerado como crítico, uma vez que o valor encontra-se dentro da faixa, de 0,7 a 1,2 $\mathrm{g} \mathrm{kg}^{-1}$, obtida pelo mesmo autor, e inferior aos resultados de Ogata et al. (1988), que fixaram a concentração crítica como sendo de 1,3 $\mathrm{g} \mathrm{kg}^{-1}$ (Quadro 3).

Para a C. ochroleuca, os teores de fósforo foram inferiores aos verificados por Sarwatt (1990). Na C. juncea, os teores de fósforo foram inferiores aos observados por Patil \& Pal (1985) e por Caceres \& Alcarde(1995), possivel mente por causa do material genético testado.

Em relação à quantidade de fósforo absorvida pelas espécies, observou-se comportamento similar ao nitrogênio na primeira e na terceira época. $\mathrm{Na}$ segunda época, o guandu sobressaiu-se em relação às demais espécies. Com o atraso da semeadura, houve diminuição da quantidade de fósforo absorvida pelo guandu, C. juncea e C. ochroleuca (Quadro 3). Contudo, a mucuna preta absorveu quantidades semel hantes nas épocas avaliadas.

As variabilidades dos teores e das quantidades de fósforo observadas, para cada leguminosa, revelaram ser possível selecionar para os Cerrados determinada espécie de adubo verde para cada época de semeadura e sistema de produção.

Quanto ao potássio, a eficiência relativa das leguminosas foi averiguada pelo agrupamento dos resultados por épocas (Quadro 4). A C. ochrol euca foi a espécie quetevetendência a apresentar maior teor de potássio, embora não di ferindo estatisticamenteda mucuna preta e do guandu. Esse teor pode ser considerado adequado, principalmente tratando-se das condições climáticas, por vezes, marginais a que foi exposta essa espécie. Por outro lado, o teor 
registrado foi superior ao nível crítico $\left(2,3 \mathrm{~g} \mathrm{~kg}^{-1}\right)$, proposto por Mukurasi, citado por Sibuga (1987). O guandu apresentou teor mais el evado do que o obtido por Nichols (1965), que foi da ordem de $7,8 \mathrm{~g} \mathrm{~kg}^{-1}$. Como essas espécies são exóticas aos Cerrados, infere-se que haja aceitável adaptação dessas espécies a este ambiente. Já a mucuna preta absorveu as menores quantidades de potássio, considerando sua menor produção de matéria seca.

Dentro do estudo das épocas de semeadura, pelo agrupamento das espécies (Quadro 5), verificou-se a ação temporal do elemento potássio, em função do deslocamento das datas de semeadura. O teor de potássio das leguminosas foi superior na segunda época, quando comparado com o dos demais períodos, mostrando a melhor adaptabilidade dos adubos verdes à extração de potássio nessa época, aliado às condições de umidade e de temperatura favoráveis.

Quadro 4. Valores médios agrupados de absorção e de teor de potássio na parte aérea das espécies de adubos verdes Crotalaria juncea, Crotalaria ochrol euca, Mucuna aterrima e Cajanus cajan

\begin{tabular}{lcc}
\hline \multicolumn{1}{c}{ Espécie } & Teor(1) & Absorção(1) \\
\hline & $\mathrm{g} \mathrm{kg}^{-1}$ & $\mathrm{~kg} \mathrm{ha}^{-1}$ \\
C. juncea & $7,9 \mathrm{~b}$ & $81,81 \mathrm{a}$ \\
C. ochrol euca & $10,3 \mathrm{a}$ & $61,95 \mathrm{ab}$ \\
Mucuna preta & $10,0 \mathrm{ab}$ & $40,50 \mathrm{~b}$ \\
Guandu & $9,7 \mathrm{ab}$ & $98,57 \mathrm{a}$ \\
C.V. \% & 16,6 & 12,2 \\
\hline
\end{tabular}

(1) Valores seguidos das mesmas letras não diferem entre si pelo teste de Tukey a $5 \%$.

Quadro 5. Valores médios do teor e de absorção de potássio na parte aérea das espécies de adubos verdes Crotalaria juncea, Crotalaria ochroleuca, Mucuna aterrima e Cajanus cajan, agrupados por épocas de semeadura

\begin{tabular}{|c|c|c|c|}
\hline & \multicolumn{3}{|c|}{ É poca de semeadura(1) } \\
\hline & $12 /$ novembro & 07/janeiro & 04/março \\
\hline & \multicolumn{3}{|c|}{ Concentração de K } \\
\hline \multirow[t]{2}{*}{$\begin{array}{l}\mathrm{g} \mathrm{kg}^{-1} \\
\text { C.V. \% }\end{array}$} & $\begin{array}{c}8,1 \mathrm{a} \\
12,6\end{array}$ & $\begin{array}{l}11,2 \mathrm{~b} \\
16,6\end{array}$ & $\begin{array}{c}9,1 \text { a } \\
18,9\end{array}$ \\
\hline & \multicolumn{3}{|c|}{ Absor ção de K } \\
\hline $\begin{array}{l}\text { kg ha-1 } \\
\text { C.V. \% }\end{array}$ & $\begin{array}{l}87,27 a \\
13,6\end{array}$ & $\begin{array}{l}81,05 a \\
12,0\end{array}$ & $\begin{array}{l}43,96 a \\
15,7\end{array}$ \\
\hline
\end{tabular}

\section{CONCLUSÕES}

1. Os teores e as quantidades absorvidas de nitrogênio, fósforo e potássio não foram influenciados pelos espaçamentos e, conseqüentemente, pelas populações empregadas.

2. Os teores e as quantidades absorvidas de nitrogênio, fósforo e potássio foram influenciados tanto pelas épocas de semeaduras como pelas espécies de leguminosas.

3. A seleção do adubo verde para fornecimento de nitrogênio, fósforo e potássio está rel acionada com a época de semeadura.

\section{LITE RATURA CITADA}

BAHAR, F.A. Cultural practices for pigeon pea (Cajanus cajan (L.) Millsp.) as a forage, green manure, and grain crops. Gainesville, University of Florida. 1981. 103p. (Tese de Doutorado)

BALAKRISHNAN, K. \& NATARAJ ARATNAM, N. Nutrient uptakein pigeon pea as influenced by sowing dates. Madras Agric. J., 76:430-437, 1989.

BALIGAR, V.C.; DUNCAN, R.R. \& FAGERIA, N.K. Soil-plant interaction on nutrient use efficiency in plants: an overview. In: BALIGAR, V.C. \& DUNCAN, R.R., eds. Crops as enhancers of nutrient use. San Diego: Academic Press, 1990. p.351-373.

BATES, T.E. Factors affecting critical concentration in plants and their evaluation: a review. Soil Sci., 112:116-130, 1971.

BHOWMIK, N.N.; GHOSH, N. \& CHOWDHURY, P.B. Effect of irrigation and phosphorus on growth and yield of pigeon pea (Cajanus cajan L.). Ind. Agric., 27:343-347, 1983.

BURLE, M.L.; RESCK, D.V.S.; SUHET, A.R. \& PEREIRA, J . Comportamento de leguminosas na estação seca da Região dos Cerrados. In: EMPRESA BRASI LEIRA DE PESQUISA AGROPECUÁRIA-EMBRAPA. Centro de Pesquisa Agropecuária dos Cerrados (Planaltina, DF). Relatório técnico anual do Centro de Pesquisa Agropecuária dos Cerrados - 1987/1990. Planaltina, 1994a. p.89-97.

BURLE, M.L.; SUHET, A.R.; PEREIRA, J . \& RESCK, D.V.S. Adubação verde no período da seca nos Cerrados: efeito na cultura do milho. In: EMPRESA BRASILEIRA DE PESQUISA AGROPECUÁRIA-EMBRAPA. Centro de Pesquisa Agropecuária dos Cerrados (Planaltina, DF). Relatório técnico anual do Centro de Pesquisa Agropecuária dos Cerrados - 1987/1990. Planaltina, 1994b. p.101-105.

CACERES, N.T. \& ALCARDE, J.C. Adubação verde com leguminosas em rotação com cana-de-açúcar (Saccharum spp). STAB. Açuc. Álcool Subprod., 13:17-20, 1995.

CHAPMAN, A.L. \& MUCHOW, R.C. Nitrogen accumulated and partitioned at maturity by grain legumes grown under different water regimes in a semi-arid tropical environment. Field Crops Res., 11:69-79, 1985. 
EMPRESA BRASILEIRA DE PESQUISA AGROPECUÁRIA EMBRAPA. Serviço Nacional de Levantamento e Conservação de Solos. Manual de métodos de análise de solo. Rio de J aneiro, 1979. não paginado

HUNDAL, H.S. \& DHILLON, N.S. Influence of green manures on $\mathrm{P}$ use efficiency in rice. Inter. Rice Res. News., 18:43-44, 1993.

KOLAR, S.J .; GREWAL, H.S. \& SINGH, B. Nitrogen substitution and higher productivity of a rice-wheat cropping system through green manuring. Trop. Agric., 70:301-304, 1993.

LAWN, R.J .\& WILLIAMS, J .H. Limits imposed by climatological factors. In: FOOD LEGUME IMPROVEMENT FOR ASIAN FARMING SYSTEMS, Canberra, 1987. Proceedings. Canberra, Australian Centrefor International Agricultural Research, 1987. p.38-98.

MAEDA, J .A. \& LAGO, A.A. Germinação de sementes de mucunapreta após tratamentos para superação da impermeabilidade do tegumento. R. Bras. Sementes, 8:79-84, 1986.

MAGALHÃES,J .C.A.J .; PEREIRA, J .; SOUZA, D.M.G.; PERES, J .R.R. \& SUHET, A.R. Eficiência da adubação verde na disponibilidade de fósforo de fosfato, numa sucessão de culturas, em solos de Cerrado. In: EMPRESA BRASI LEIRA DE PESQUISA AGROPECUÁRIA-EMBRAPA. Centro de Pesquisa Agropecuária dos Cerrados (Planaltina, DF). Relatório técnico anual do Centro de Pesquisa Agropecuária dos Cerrados - 1985/1987. Planaltina, 1991. p.112-117.

MALAVOLTA, E. Elementos denutrição mineral de plantas. São Paulo, Agronômica Ceres, 1980. 251p.

MALAVOLTA, E.; VITTI, G.C. \& OLIVEIRA, S.A. Avaliação do estado nutricional das plantas: princípios e aplicações. Piracicaba, POTAFOS, 1989. 201p.

NANDWAL, A.S.; BHARTI, S.; SINGH, I. \& KUNDU, B.S. Nitrogen partitioning and its efficiency in pigeon pea under drought and during recovery. Ind. J . Plant Physiol., 35:364370, 1992.

NICHOLS, R. Studies on the major-element deficiencies of the pigeon pea (Cajanus cajan) in sand culture. II. The effects of major-element deficiencies on nodulation, growth and mineral composition. Plant Soil, 22:112-126, 1965.

OGATA, S.; ADU-GYAMFI, J . \& FUJ ITA, K. Effect of phosphorus and $\mathrm{pH}$ on dry matter production, dinitrogen fixation and critical phosphorus concentration in pigeon pea (Cajanus cajan (L.) Millsp.). Soil Sci. Plant Nutr., 34:55-64, 1988.

PATIL, B.P. \& PAL, M. I nvestigations on growth, energy output, chemical composition and mineral uptake by legumes intercropped with transplated pearlmillet. Ind. J . Agron., 30:181-186, 1985.
PEREIRA, J. Avaliação das características agronômicas de leguminosas adubos verdes no Cerrado. In: EMPRESA BRASILEIRA DE PESQUISA AGROPECUÁRIA EMBRAPA. Centro de Pesquisa Agropecuária dos Cerrados (Planaltina, DF). Relatório técnico anual do Centro de Pesquisa Agropecuária dos Cerrados - 1985/1987. Planaltina, 1991. p.111-112.

QUINTANA, J.O. Evaluation of two procedures for screening legume green matures as nitrogen sources to succeeding corn. Ithaca: Cornell University, 1987. 181p. (Tese de Doutorado)

RAIJ , B. van. Fertilidade do solo e adubação. São Paulo: Agronômica Ceres/POTAFOS, 1991. 343p.

REDDY, K.C.; SOFFES, A.R. \& PRINE, G.M. Tropical legumes for green manure. I. Nitrogen production and the effects on succeeding crop yields. Agron. J ., 78:1-4, 1986.

REUTER, D.J . Temperate and sub-tropical crops. In: REUTER, D.J. \& ROBINSON, J.B., ed. Plant analysis: an interpretation manual. Melbourne, Inkata, 1986. p.38-99.

SARRUGE, J .R. \& HAAG, H.P. Análises químicas em plantas. Piracicaba, Escola Superior deAgricultura Luiz deQueiroz, 1974. 56p.

SARWATT, S.V. Feed intake, growth rate and digestibility coefficients of growing sheep fed hay supplemented with Crotalaria ochroleuca. Anim. Feed Sci. Technol., 28:51-59, 1990.

SHARMA, K.N.; BHANDARI, A.L.; RANA, D.S.; KAPUR, M.L. \& SODHI, J.S. Crop yield, nutrient uptake and soil properties as influenced by components of crop technology in a pigeon pea - wheat sequence. J. Ind. Soc. Soil Sci., 38:520-523, 1990.

SIBUGA, K.P. Weed suppression by Crotalaria ochroleuca. In: WRITERS' WORKSHOP ON THE ROLE OF MAREJ EA (Crotalaria ochroleuca) IN AGRICULTURAL PRODUCTION IN TANZANIA, Paramiho. 1986. Proceedings. Paramiho, Benedictine Public. Ndanda Paramiho, 1987. p.30-31.

SOUSA, D.M.G. \& LOBATO, E. Adubação fosfatada. In: SIMPÓSIO SOBRE O CERRADO, 6., Brasília, 1982. Savanas: alimento eenergia. Planaltina, EMBRAPA-CPAC, 1988. p.33-60.

WILSON, J.R. Effects of water stress on in vitro dry matter digestibility and chemical composition of herbage of tropical pasture species. Aust. J . Agric. Res., 34:377-390, 1983.

WILSON, J .R. \& MUCHOW, R.C. Effects of water stress and dry matter digestibility and concentration of nitrogen and phosphorus in seven tropical grain legumes. J. Aust. Inst. Agric. Sci., 49:167-169, 1983. 